Revista cla ANPOLL, n" 5, p. 139-150, jul./de\%, 1998

\title{
A EMERGENCIA DA FUNÇĀO POÉTICA NOS TEXTOS ESCRITOS PRODUZIDOS POR UM ADULTO QUE APRENDEU A LER E ESCREVER NA PRISĀO
}

Leda Verdiani'Tfoumi"

\begin{abstract}
MBSUIIO: Esste urabalho relata uma experiência com um método de alfabelizaçĩo cle codullos construíclo por mim, denominudes "mélodo discursivo". Apresenta ainda

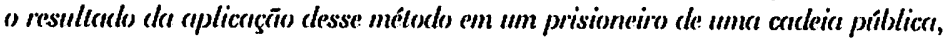

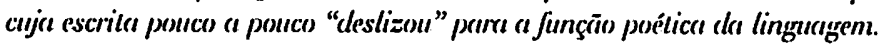

PAIAVMAS-CIIIVE: Alfabelizaçüo de codullos; método discursion; funçño poélica da lingaragem.

\section{INTRODUÇĀO}

G stc trabalho retoma algumas publicaçōcs antcriores, nas quais

E contextualizo historicamente o que scrá aqui tratado. (Por cxemplo, 'I'founi, 1992, 1994, 1996a,b). Em síntesc, trata-se do scguinte: Ilá quasc uma década, venho oferecendo à conunidade um programa de alfabctização de adultos que ć coordenado por mim c concluzido por alunos(as) da graduação cm Psicologia da USP de Ribcirão Preto. Sob a forma de disciplina-estágio, semestralmente os alunos(as) podem matricular-sc c participar desta expcriência única dentro de uma cstrutura curricular; cujo objctivo é preparar profissionais para atuarem na árca de alfabctização de adultos, quer $\mathrm{cm}$ projetos institucionais, quer fora deles, em caráter alternativo. Dentro destc projeto de extensão de serviços, desenvolvi um método de alfabctização de adultos, que denomino de método discursivo, do qual falarei brevemente mais abaixo.

11.

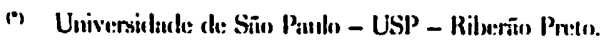




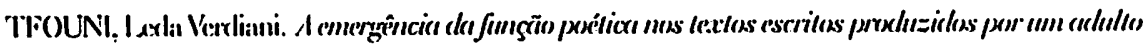
que coprenden a ler e escrever na pristion.

Continuando a descrição da estrutura desse serviço, acrescento que: o trabalho é desenvolvido através de sessōes scmanais de supervisão, durante as quais os(as) cstagiários(as) são oricntados sobre o tipo de atividades que deverão desenvolver na semana posterior; bem como sobre os recursos c/ou matcriais de auxílio didático-pedagógógico c leituras suplementares de que precisarão. Cada dupla de estagiários(as) tem a incumbência de montå uma turma de adultos ou adolescentes não-alfabetizados, ou com um conhecimento inicial da escrita. Do mesmo modo, o local onde as aulas scrão ministradas, bem como o horário mais conveniente para as aulas ficam dependendo de uma negociação entre estagiários(as) e o fiuturo grupo-classe. Os cursos são desligados da estrutura formal da escola. Não há matrícula, controle de presença, provas, prazo para início ou término, controle do número de alunos. lim geral as aulas são dadas três vezes por scmana, c têm a duração de uma hora c trinta minutos cada, o que perfaz um total de quatro horas e meia de aula por semana.

Nestes anos todos, as dezenas de turmas com as quais já traballaamos localizaram-se em diversos bairos com baixa concentraçĩo de renda de Ribcirão Preto, muitas vezes em favelas, outras em casas paroquiais, ou ainda em organizaçōes que prestam assistência à comunidade carente dà cidade, como é o caso da liundação Vida Nova, que atende crianças de rua, ou à Oficina de Marcenaria, que desenvolve um projeto de educaç̃̃o pelo trabalho. Lim algumas ocasiōes, ultrapassamos os limites da cidade, c fomos até cidades próximas. Assim, por cxempolo, uma destas turmas foi montada com cinco detentos de uma cadeia pública da cidade de Scrtãozinho, próxima a Ribcirão Preto, por duas (na época) alunas da graduação, Ana Paula Soares da Silva c Rosa Virgínia Pantoni. Ultrapassando uma séric de dificuldades de todo tipo, desde exigências burocráticas (como por exemplo, a necessidade de escolta para que os presos pudessem ir até o local das aulas) até a má vontade das autoridades e a falta de respeito pelo espaço onde desenvolviam scu trabalho (no início, os gualldas que faziam a escolta andavam pela sala, ou cntão postavam-se ì por- 


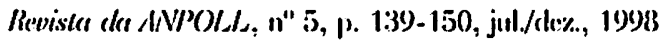

ta c licavam fazendo comentários inadequados sobre a atividade pedagógica), ambas persistiram durante quatro meses, c conseguiram um resultado final com um dos alunos, Mário (nome fictício, em homenagem a três Mários da literatura brasilcira: Quintana, Palmério, c de Andrade), resultado este que ao mesmo tempo que aponta para a demonstıação de que o analfabetismo no Brasil tem solução, também serve de manifesto acerca da força que tem um método voltado para as verdadeiras questōes envolvidas $\mathrm{cm}$ programas de alfabctizaçāo.

Retomando, é deste aluno especificamente que pretendo falar aqui, devido à importância que tem para aqueles que trabalham na área de letramento c alfabetizaçĩo, os resultados que foram obtidos com cle durante o processo de aquisição da escrita: scus textos revelam claramente um direcionamento para a função poćtica da linguagem, conforme irei mostrar mais à frente. Antes de apresentar os dados, farci uma breve descrição da fundamentação teórica do método discursivo, bem como do funcionamento geral do programa.

\section{O MÉTODO DISCURSIVO: APRESENTAÇĀO}

Não é mcu objetivo alongar-me aqui na descrição do método, mesmo porque isto já foi objeto de trabalhos anteriores meus (c. g., 'T'louni, $1996 a, b)$.

A fundamentação teórica ampla deste método situa-se cm uma zona de interface da Análise do Discurso francesa (Pêcheux, 1988; Orlandi, 1987a), da Psicolinguiistica de base sociointeracionista (de L_cmos, 1982) c da Ijingiiística Aplicada (Klciman, 1995). Mais especificamente, oferecendo um suporte cm termos das colocações mais recentes acerca do conceito de allabetizaçĩo e seu redirecionamento, sĩo usados os traballos de 'Tfouni (1995a) sobre o conceito de letramento, c o de (Jallo (1992) solore o discarso da escrila. 


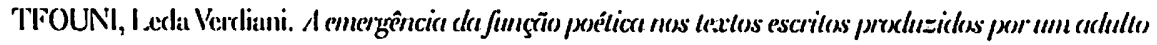
que riprendeu a ler e escrever na prisios.

O objetivo geral do processo ć promover a iuscrção dos alfabetizandos naquelas práticas letradas de sua cultura que fazcm algum scntido dentro de suas atividades cotidianas de trabalho, lazer; ctc. Assim, não há adoção de livros-textos, cartilhas, ou qualquer outro matcrial didático comercializado. O ensino da lcitura/cscrita sc dá através da produção dos textos que os próprios alunos descjam claborar: Deve-sc obscrvar que tais textos nunca ocorrem "desencarnados" de scu suporte sócio-histólico: explora-sc scmpre o portador que cstá sendo produzido juntamente com o texto, de tal modo que o processo de integração entrc cscrita/lcitura/atividadc comunicativa c prática social ć completo.

A rclação cm sala de aula ć caractcrizada mais por uma troca de papéis do que pela assimctria clássica professor/aluno. (O ponto de partida é sempre aquilo que o aluno já sabe, c o ponto de chegada é aquele que o aluno descja atingir: O professor descmpenha uma funçĩo de mediador; muito semelhante àquela proposta por Vygotsky (1984) para desciever o papel do adulto como responsável pelo processo de ingresso da criança no simbólico. O objetivo de fim de processo é oferecer aos alunos oportunidades para que se apropriem do papel de autores de sua escrita. 'Tal possibilidade de autoria é marcada lingüisticamente principalmente pela coesão, mas também tem a caractcrística de um deslocamento con relação aos mecanismos de paráfrase e reprodução de sentidos que predominam na cscola. Deste modo, os produtos cscritos dos alunos, após poucos meses de aulas, podem ser caracterizados pela criatividade (no sentido dado por Orlandi, 1987b).

Conccitos tais como os de segmentação, texto, portador de texto, unidade, recorte ctc. são aprendidos pclos(as) estagiários(as) durante a supcrvisão, $\mathrm{c}$ todo um trabalho prático decorrc disso.

De acordo com este método de alfabetização de adultos, as classes não são tratadas como sc fosscm todas iguais. O ponto de particla ć cxatamente a difcrença. Ássim, cadx grupo cncaminha o aprendizado para arüüelas necessidades cotıdianas específicas nas quais a escrita lhes faz falta. 
Revista da INPOLIL, n" 5, p. 139)-150, jull/dlo\%., 1998

ć aqui retomada, mas não mais no tom nostálgico e deprimido cpuc está presente na quadra anterior: Desta vez, o tom é de desafio, de vigor: Este rapaz, já um cscritor; cstá sem dúvida sentindo-se mais forte, c com certcza parte dessa sensação de poder tem origem no domínio da escrita. No texto abaixo, Mário cxpressa de forma ainda mais sofisticada esse duplo caminho (função poética/ temática da liberdade) que sua cscrita toma:

\begin{abstract}
LICRMMLAS

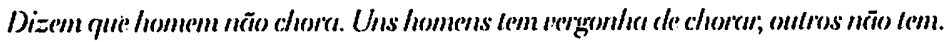

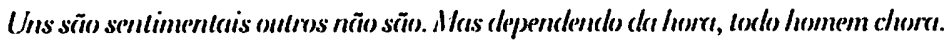
Se é por amor; se é por dornça, as lägrimess rolam. Aluris dess groules tanta gante.

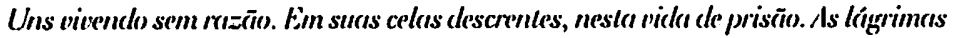

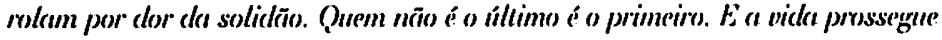
assim uns rindo, outros chorando.
\end{abstract}

O que atrai a atenção no texto acima (já cstruturado como texto genuíno) é o uso consistente da rima (hora/chora; amor/dor; gente/descrente; razão/prisão/solidão). Aparentemente, Mário começou a tomar consciência de que podia "brincar" com os sons das palavras após ler alguns livios de cordel que as estagiárias levaram para a aula, pelos quais interessou-se bastantc. Desta cspécic de insight, lado a lado com o sofirmento pessoal que demonstrava pelo fato de cstar preso (a metáfora sobrc a liberdade aparece nesse texto de forma incipiente), Mário completa o processo de deslizamento de sua cscrita em dirção à função poćtica da linguagrem (cf. Jakobson, 1995). Por cxcmplo, cm uma carta para a mãc, cle escreve:

Mil:

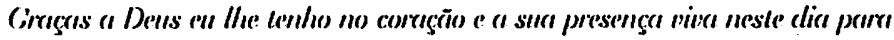
mim agroudecer:

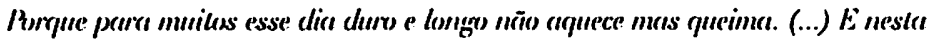
horra sem mäe, é unma horra vazia, com muito de scauducte e de lembranga. 


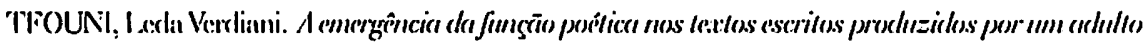
que coprenclen a ler a escrever ner prission.

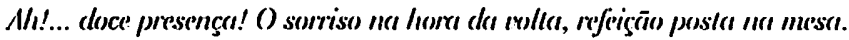

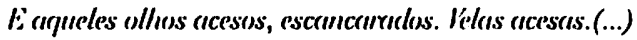

É emocionante perceber os recursos cstilísticos de que $M$. faz uso no texto acima. Metáforas c metonímias, cue com certeza não se aprendem na escola, nem dependem do grau de letramento da pessoa, mesclam-se para formar uma bela peça, delicada c sensível. A escrita aqui está claramente servindo a uma função catártica, apaziguadora do sofirimento deste rapaz.

$4^{\text {A }}$ Fase - A última fase do processo de letramento-alfabetizaçĩo de M. está claramente marcada pelo predomínio da função poćtica (não por acaso, lembro cu, visto que $M$. qucria ser macstro, c pocsia c música são inseparávcis). Para ilustrar isto, sclecionci a pocsia que se seguc:

ICURYA DOAZUL

l'ócî salke o que é uma propoula?

É uma bortzoleta que virou flor

Eis mes vồ silenciosso solene liure

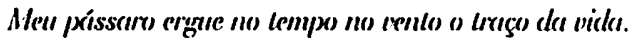

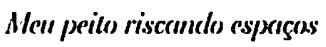

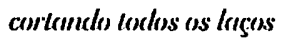

livre, infinits enfim.

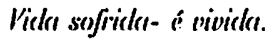

Aleu tempos riil e chorrou...

Que é da minha amada?- O sempre impossivel sonhio-

tè espero na currer do cazul...

\section{CONCLUSÕES}

Procurci apresentar cvidências, através da análise de darlos, de que uma proposta de alfabctização centrada na noção de diferença, e que su- 


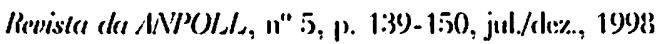

pố o conccito de letramento é capaz de operar profundas transformaçōes nas pessoas que aprendem a ler e escrever. Descrevi um método construído por mim ao longo de vários anos de trabalho com alfabetização de adultos, método este cue denomino de método discursivo, porque tem como proposta central liclar com o sujcito da escrita enquanto uma posição discursiva que pode ser ocupada por todos. Esta posição, dentro do método aqui proposto é tal que permite uma série de deslizamentos efetuados dentro do próprio processo de domínio das práticas letradas, deslizamentos estes que têm como característica principal o fato de que permitem ao sujcito usar a escrita para falar de si, de scus problemas, de suas necessidades, de scus descjos. Linfim, este método permite que a subjetividade tome o lugara da reprodução e da paráfrase que predominam nos métodos tradicionais. No caso aqui estudado - o de um prisionciro que aprendeu a ler c escrever na prisão - vimos como o domínio das técnicas cscritas veio acompanhado de uma conscientização de sua problemática pessoal, c evoluiu claramente em diregão à função poćtica da linguagem. Certamente este poeta não teria nasciclo, se tivéssemos nos preocupado apenas com o ensino dos rudimentos da leitura/escrita, ou com as habilidades funcionais dos usos da escrita. (CNPq, FAPESP, CAPES).

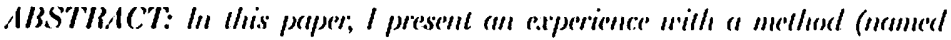

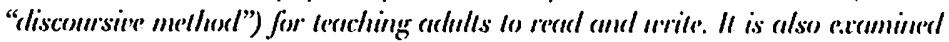

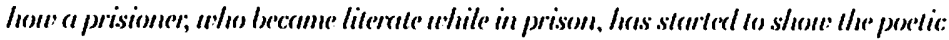
finnction of lenganage in his uritings.

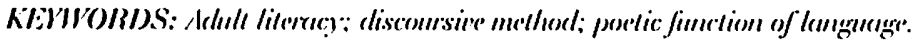

\section{BIBLIOGRAFIA}

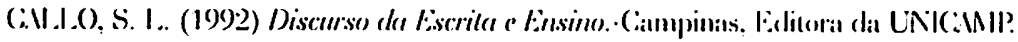

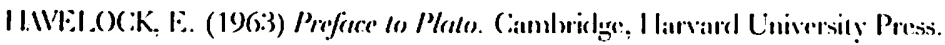




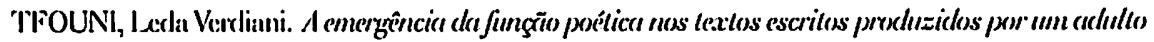
que aprendeu a ler e escrever na prisaio.

JAKOBSON, R. (1995) Lingüistica e poética. In R. Jakobson. Lingüïstica e Commuicaģüo. Sĩo Paulo, Cultrix, p. 118-162.

KI_LIMAN, A. B. (Org.). (1995) Os Significados do Letromento. Campinats, Mercarlo de L_etrats.

LEMOS, C. T. G. de (1982) Sobre aquisição da linguargem e seu dilema (pecado) original. Boletim da Abralin, 3, p. 97-125.

ORI_ANDI, E. P. (1987 a) A Linguregem e seu Funcionamento. Campinats, UNICAMII? (1987 b) O sentido dominante: a literalidade como prodento da /listórira. In li. I?. Orlandi. A Linguagem e seu Funcionamento. Campinas, UNICAMP, p. 135-148.

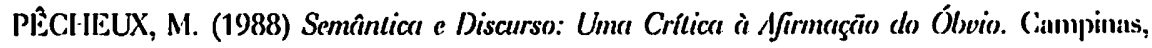
UNICAMP.

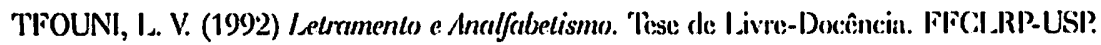

(1995 a) /eloramentos e Alfabetizaçüo.Sño Paulo, Cortc\%.

(1995 b) Sujeito da escrila e sujeito do letramento: Coincidência? In L. V. Tfouni. Leluramenlos e Alfabelizaçäo. Süo Paulo, Corte\%.

(1996 a) Letramento e alfabetizaçĩo de adultos. Thaballoso apresentado em mesiaredonda durante a Reunião da $\mathrm{NNPOI}$, João Pessoa, PB.

(1996 b) A escolaridade é um crilério adequado para cavaliar o grruu de leturumentón nos poíses de Terceiro Mundo? Traballo apresentado cm simpósio durante o Congresso Internacional da NIL $\Lambda$, Jyväskylï, Fünlândia.

VYCOTSKY, I. S. (1984) A Formaģäo Social da Mente. São Paulo, Martins l'ontes. 